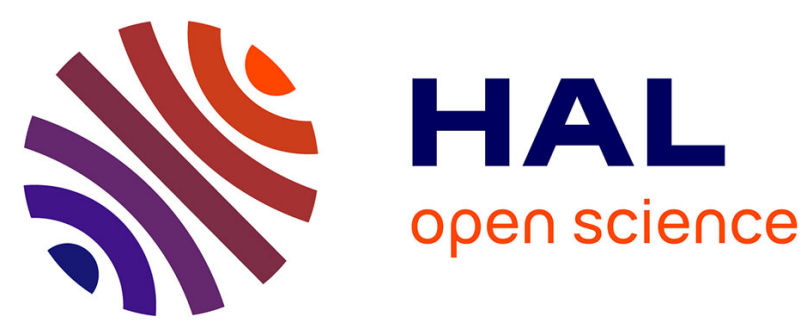

\title{
Modular synthesis of pentaarylcyclopentadienyl Ru-based molecular machines via sequential Pd-catalysed cross couplings
}

Yohan Gisbert, Seifallah Abid, Gaëlle Bertrand, Nathalie Saffon-Merceron, Claire Kammerer, Gwénaël Rapenne

\section{To cite this version:}

Yohan Gisbert, Seifallah Abid, Gaëlle Bertrand, Nathalie Saffon-Merceron, Claire Kammerer, et al.. Modular synthesis of pentaarylcyclopentadienyl Ru-based molecular machines via sequential Pd-catalysed cross couplings. Chemical Communications, 2019, 55 (97), pp.14689-14692. $10.1039 / \mathrm{c} 9 \mathrm{cc} 08384 \mathrm{~g}$. hal-02417227

\section{HAL Id: hal-02417227 \\ https://hal.science/hal-02417227}

Submitted on 10 May 2020

HAL is a multi-disciplinary open access archive for the deposit and dissemination of scientific research documents, whether they are published or not. The documents may come from teaching and research institutions in France or abroad, or from public or private research centers.
L'archive ouverte pluridisciplinaire HAL, est destinée au dépôt et à la diffusion de documents scientifiques de niveau recherche, publiés ou non, émanant des établissements d'enseignement et de recherche français ou étrangers, des laboratoires publics ou privés. 


\title{
Modular synthesis of pentaarylcyclopentadienyl Ru-based molecular machines via sequential Pd-catalysed cross couplings
}

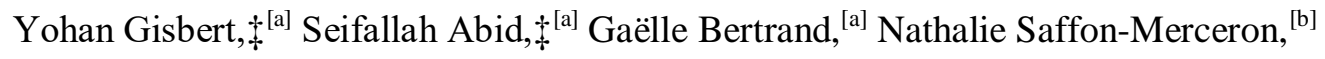 \\ Claire Kammerer, ${ }^{[\mathrm{a}]}$ and Gwénaël Rapenne*[a,c]
}

a. CEMES, Université de Toulouse, CNRS, 29, rue Jeanne Marvig, 31055 Toulouse, France.

E-mail: rapenne@cemes.fr

b. Université de Toulouse, UPS, Institut de Chimie de Toulouse, ICT FR 2599, 118 route de Narbonne, 31062 Toulouse, France.

c. Division of Materials Science, Nara Institute of Science and Technology, 8916-5 Takayama, Ikoma, Nara, Japan.

$\ddagger$ Both authors contributed equally to the project.

\begin{abstract}
A dissymmetric piano-stool ruthenium(II) complex bearing different halogens on the rotor part was efficiently prepared and subsequently used as key building block in the modular synthesis of rotative molecular machines via palladium-catalysed "Sonogashira/Suzuki-Miyaura" sequences. Applying this novel synthetic route to various cross-coupling partners, prototypes of molecular winches and gears specifically designed for studies at the single-molecule scale were efficiently obtained.
\end{abstract}

Preprint

Submitted to Chemical Communications 
Technomimetic molecules ${ }^{1}$ are compounds designed to resemble macroscopic machinery at the molecular level, also transposing the motions that these objects are able to undergo. Among them, rotative molecular machines including motors have attracted a lot of attention ${ }^{2}$ but only a few have efficiently been used to produce a work ${ }^{3}$ or have been studied at the single molecular scale level. ${ }^{4}$ In this context, we designed and synthesised a family of molecular motors based on ruthenium(II) halfsandwich complexes, bearing a pentaarylcyclopentadienyl ligand as rotor and a hydrotris(indazolyl)borate ligand as stator. ${ }^{5}$ On-surface studies by Scanning Tunneling Microscopy (STM) highlighted the prime importance of structural dissymmetry in the rotating subunit, as a source of directionality ${ }^{6}$ and as a tag to monitor the induced motion. ${ }^{7}$ Indeed, the ruthenium complex incorporating four identical $p$-ferrocenylphenyl substituents and one different tolyl group on the cyclopentadienyl ligand was shown to undergo unidirectional and reversible motion when fuelled with electrons. ${ }^{6}$ Following this result, our current work aims at the determination and exploitation of the motive power of such a motor. A structurally analogous molecular winch was thus designed by extending the truncated arm with an amide-based linker and a long polyethylene glycol (PEG-24) chain in view of single-molecule atomic force microscopy (AFM)-based force spectroscopy measurements (Fig. 1, right). ${ }^{8}$ Additionally, a preliminary synthetic study towards molecular gears was recently performed, yielding ruthenium complexes with five identical $1 \mathrm{D}$ or $2 \mathrm{D}$ fragments surrounding the pentaphenylcyclopentadienyl core via five-fold Suzuki-Miyaura or Sonogashira cross-couplings. ${ }^{9}$ The resulting prototypes all involve $C_{5}$-symmetric cogwheels, which will presumably preclude direct evidence of a possible transfer of motion within a train of such gears. To ease on-surface studies and gain deeper understanding of mechanics at the molecular scale, it appears crucial to provide molecular gears bearing a dissymmetrised cogwheel (Fig. 1, left).
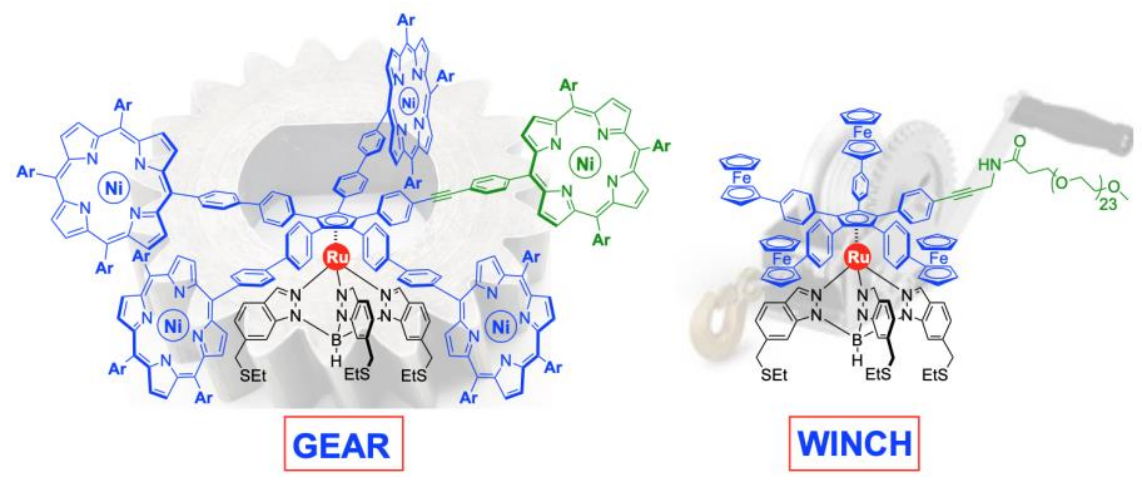

Fig. 1 Targeted new rotative molecular machines for on-surface mechanical studies: a dissymmetric gear and $a$ winch.

In this communication, we thus report the synthesis of two new prototypes of Ru-based rotative molecular machines, such as a gear and a winch, via a highly modular synthetic strategy.

With a view to accessing a family of ruthenium complexes incorporating one discriminated arm on the cyclopentadienyl ligand, we opted for a modular strategy involving late-stage functionalisation of a 1,2,3,4,5-penta( $p$-halogenophenyl)cyclopentadienyl hydrotris(indazolyl)borate ruthenium(II) precursor. Such key intermediates may be engaged in various transition metal-catalysed cross-coupling reactions to yield target molecules with high structural diversity, as reported for the synthesis of diverse 
molecular motors and gears. ${ }^{10}$ However, in contrast to previous work leading to symmetrical cyclopentadienyl platforms through five- fold cross-couplings, discrimination of one position out of five is now required.

A Suzuki-Miyaura cross-coupling was first investigated to functionalise one single position under statistical conditions starting from the pentabrominated key precursor. ${ }^{11}$ Poor efficiency was observed, even after optimisation, and low yields of the desired mono-biphenylene product, mixed with products of polysubstitution, were obtained due to the equivalence of the five independent brominated positions. It was thus envisioned to discriminate one halogen position in the 1,2,3,4,5-penta( $p$ halogenophenyl)cyclopentadienyl ruthenium(II) precursor, taking advantage of the enhanced reactivity of aryl iodides compared to aryl bromides in palladium-catalysed cross-couplings, and more particularly under Sonogashira conditions. ${ }^{12}$ Dissymmetric key precursor 1 (Scheme 1) incorporating one preactivated $p$-iodophenyl group was thus designed, to allow for chemoselective monofunctionalisation and subsequent preparation of dissymmetric rotary molecular machines bearing high structural diversity via sequential cross-coupling reactions.

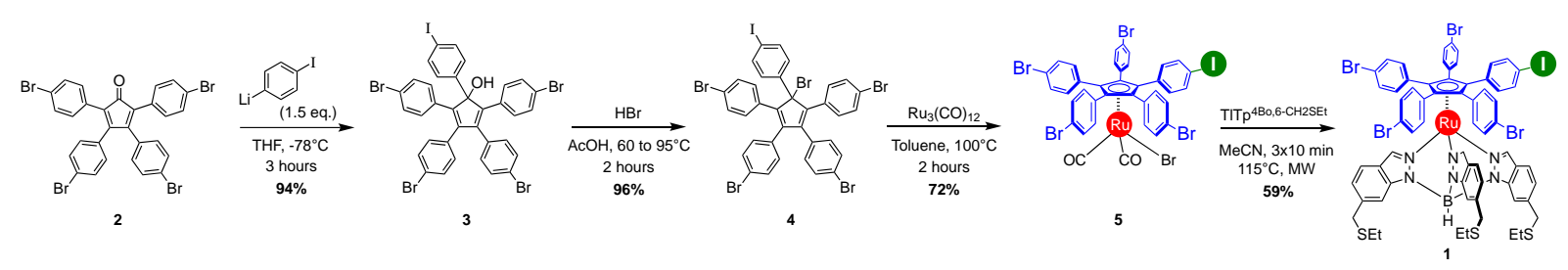

Scheme 1 Synthesis of 1-(p-iodophenyl)-2,3,4,5-tetra(p-bromophenyl)cyclopentadienyl hydrotris (indazolyl)borate ruthenium(II) (1).

1-(p-Iodophenyl)-2,3,4,5-tetra( $p$-bromophenyl)cyclopenta-dienyl

hydrotris(indazolyl)borate ruthenium(II) complex $\mathbf{1}$ was synthesised in four steps starting from 2,3,4,5-tetra( $p$ bromophenyl)cyclopenta-2,4-dienone 2 (Scheme 1). 1,2-Addition of 4-iodophenyllithium at $-78{ }^{\circ} \mathrm{C}$ afforded the corresponding cyclopentadienol 3 in $94 \%$ yield. Subsequent bromination under acidic conditions, using a mixture of hydrobromic and acetic acids, led to the corresponding bromocyclopentadiene 4, obtained as a 1:2:2 mixture of regioisomers in $96 \%$ yield. Oxidative addition onto $\mathrm{Ru}_{3}(\mathrm{CO})_{12}$ was then performed in toluene at $100{ }^{\circ} \mathrm{C}$ to provide bromidodicarbonylruthenium(II) complex $\mathbf{5}$, carrying a dissymmetrised penta( $p$-halogenophenyl)cyclopentadienyl ligand. It is important to note that no competitive insertion of ruthenium into the $\mathrm{C}_{\mathrm{Ar}} \mathrm{I}$ bond was observed, in spite of the high reactivity of such position towards oxidative addition. The yield of $72 \%$ in this chemoselective step is similar to that obtained with the analogous symmetrical hexabrominated precursor, thus demonstrating that the presence of the $p$-iodophenyl substituent has no negative effect on this reaction. Finally, ligand exchange on complex $\mathbf{5}$ in the presence of thioether-functionalised thallium hydrotris(indazolyl)borate $\mathrm{TITp} \mathrm{p}^{4 \mathrm{Bo}, 6-\mathrm{CH} 2 \mathrm{SEt}}$ in acetonitrile under microwave irradiation gave the desired 1-( $p$-iodophenyl)-2,3,4,5tetra(p-bromophenyl)cyclopentadienyl hydrotris (indazolyl)borate ruthenium(II) complex $\mathbf{1}$ in 59\% yield. As expected, lowering the symmetry of the Cp ligand renders NMR spectra more complex compared to the symmetrical counterparts. ${ }^{9,13}$ However, combination of mass spectrometry giving the expected mass and isotopic distribution (see ESI) and 2D NMR unambiguously confirmed the presence of a single $p$-iodophenylene and four $p$-bromophenylene units surrounding the central cyclopentadienyl ring. Free rotation within the complex was evidenced at room temperature by the chemical equivalence of the three indazole groups. 
Single crystals were also obtained by slow evaporation of a solution of complex $\mathbf{1}$ in a 1:1 mixture of dichloromethane and methanol, allowing us to resolve the structure by X-ray diffraction (Figure 2) ${ }^{14}$ In the structure, only one brominated position is distinct, the four others corresponding to a combination of bromine and iodine densities, due to different orientations of the molecule in the crystal.

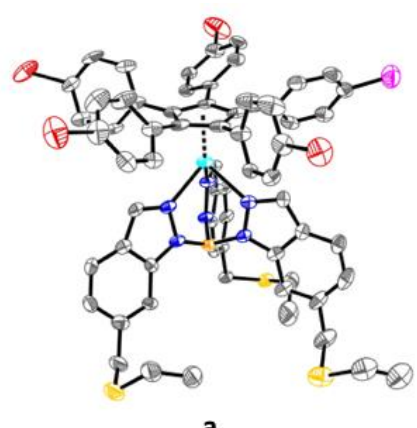

a

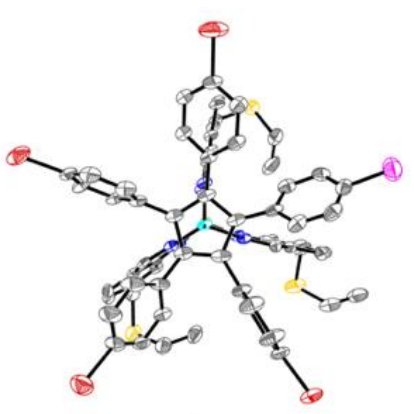

b

Fig. 2 Side view (a) and top view (b) of the molecular structure of ruthenium complex 1. Thermal ellipsoids drawn at 50\% probability, hydrogen atoms, solvent molecules and disordered atoms are omitted for clarity. The cp ligand is distant of the ruthenium atom by $1.79 \AA$ and the average distance between the three coordinated nitrogens and the ruthenium centre is $2.26 \AA$.

Complex 1, carrying one pre-activated $p$-halogenophenyl moiety, was next exploited as key building block for the modular and selective synthesis of rotary molecular machines. In our work dedicated to the synthesis of molecular gears prototypes involving porphyrins as bidimensional paddles, the cogwheel diameter was modulated as a function of the nature of the spacer between the cyclopentadienyl platform and the porphyrin. Starting from symmetrical penta( $p$-halogenophenyl) cyclopentadienyl ruthenium(II) precursors, molecular gears prototypes with shorter 4,4'-biphenyl and longer phenylethynylphenyl linkers were obtained via five-fold Suzuki-Miyaura or Sonogashira crosscouplings, respectively, in the presence of the appropriate porphyrinic partner. ${ }^{8}$ It is now envisioned to exploit the length of the linker as a strategy to differentiate one paddle, while keeping the same structure for all of them. Indeed, this structural modification leading to dissymmetrised cogwheels including one longer arm will facilitate STM studies on surface, with a direct monitoring of the molecular motion.

In our efforts towards the synthesis of symmetrical cogwheels, five-fold Sonogashira cross-coupling reactions on the symmetric penta( $p$-iodophenyl)cyclopentadienyl ruthenium(II) precursor were performed using $\mathrm{PdCl}_{2}\left(\mathrm{PPh}_{3}\right)_{2}$ and $\mathrm{CuI}$ as the catalytic system in triethylamine at $45{ }^{\circ} \mathrm{C}^{9}$ Further investigations revealed that the pentabrominated analog is also prone to Sonogashira couplings with similar yield under much harsher conditions involving $\mathrm{Pd}(\mathrm{OAc})_{2} / \mathrm{SPhos}$ and $\mathrm{CuI}$ as catalytic system in a DMF/diisopropylamine mixture at $95{ }^{\circ} \mathrm{C}$. The striking difference in reaction conditions for the conversion of $p$-iodophenyl and $p$-bromophenyl precursors opened the way for the chemoselective functionalisation of $\mathbf{1}$ via successive cross-coupling reactions. 


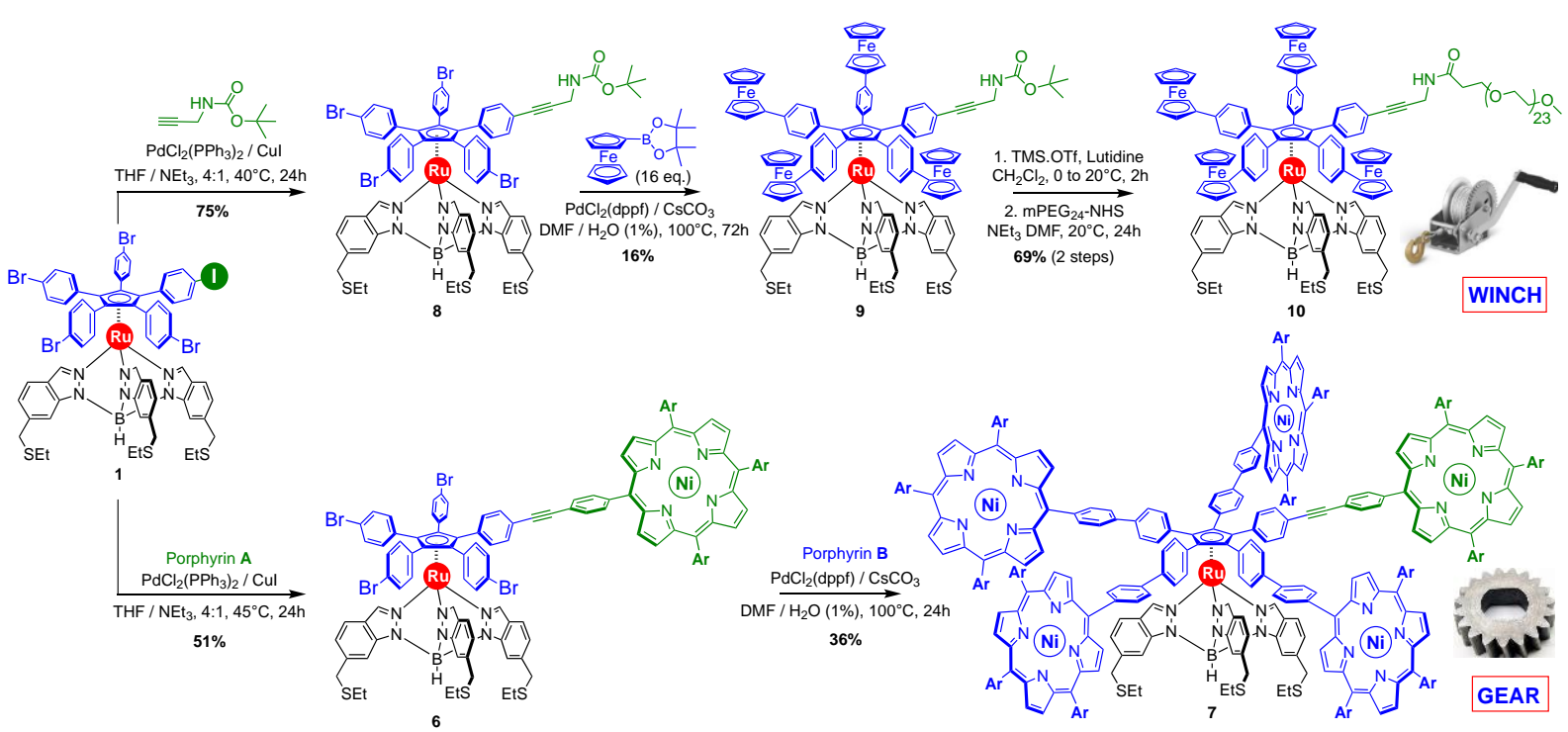

Scheme 2 Synthetic route to the molecular winch (11) and dissymmetric gear (7). Porphyrin $\boldsymbol{A}$ is Nickel(II) 5-(4-ethynylphenyl)-10,15,20-tris(3,5-di-tert-butylphenyl)porphyrin and Porphyrin $\boldsymbol{B}$ is Nickel(II) 5,10,15-tris(3,5-di-tert-butylphenyl)-20-[4-(4,4,5,5-tetramethyl-1,3,2-dioxaborolan-2-yl) phenyl)]porphyrin. $\boldsymbol{A r}=3,5$ di-tert-butylphenyl.

Reaction of key precursor $\mathbf{1}$ with 1.5 eq. of $\mathrm{A}_{3} \mathrm{~B}$-type porphyrin $\mathbf{A}$ bearing a terminal alkyne (Scheme 2) was thus carried out under mild conditions in the presence of $\mathrm{PdCl}_{2}\left(\mathrm{PPh}_{3}\right)_{2}(1 \mathrm{~mol}-\%)$ and $\mathrm{CuI}(0.6 \mathrm{~mol}-$ $\%)$ as catalysts in a mixture of tetrahydrofuran and triethylamine (4:1). After $24 \mathrm{~h}$ at $45^{\circ} \mathrm{C}$, product 6 resulting from a single Sonogashira coupling was isolated as a red solid in 51\% yield. Interestingly, it was observed during optimisation that an increase of temperature up to $80^{\circ} \mathrm{C}$ leads to the formation of a mixture of bis-porphyrin functionalised side-products resulting from an additional Sonogashira coupling on a bromophenylene position. In the next step, a four-fold Suzuki-Miyaura cross-coupling was achieved on $\mathbf{6}$, in order to functionalise the remaining $p$-bromophenylene groups and introduce the four shorter 4,4'-biphenyl linkers. Complex 6 was thus reacted with 8 eq. of an $\mathrm{A}_{3} \mathrm{~B}$-type porphyrin $\mathbf{B}$ bearing a boronic ester (Scheme 2) as coupling partner, in the presence of $\mathrm{PdCl}_{2}(\mathrm{dppf})(10 \mathrm{~mol}-\% / \mathrm{Br})$ as catalyst and a large excess of cesium carbonate as base in a DMF/water (99:1) system. ${ }^{9}$ After $48 \mathrm{~h}$ at $100{ }^{\circ} \mathrm{C}$, complex 7 incorporating five identical porphyrin fragments but different spacers was isolated in $36 \%$ yield (i.e. $77 \%$ per single coupling). The structure of this molecular gear prototype carrying a dissymmetric cogwheel was unambiguously confirmed by mass spectrometry and NMR spectroscopy, revealing the presence of one longer phenylethynylphenyl and four short 4,4'-biphenyl linkers around the central cyclopentadienyl moiety. The UV-visible spectrum of compound $\mathbf{7}$ resembles that of $\mathbf{6}$, with a Soret band at $418 \mathrm{~nm}$ and a Q band at $529 \mathrm{~nm}$. No shift of these bands was observed but an additive effect was noticed, with an increase of the molar extinction coefficients (e.g. from 254000 in 6 to 1396 $000 \mathrm{~mol}^{-1} \mathrm{dm}^{3} \mathrm{~cm}^{-1}$ in 7 for the Soret band, see ESI) in line with the number of porphyrin units present in such molecules.

This first example of dissymmetric ruthenium-based molecular gear was thus obtained in two steps, via successful sequential chemoselective Sonogashira / four-fold Suzuki-Miyaura cross-couplings from key intermediate $\mathbf{1}$, bearing one pre-activated position.

The same synthetic strategy relying on building block $\mathbf{1}$ was considered for the preparation of a molecular winch prototype. The latter was designed in view of single molecule force spectroscopy experiments to investigate the motive power of the ruthenium-based molecular motor previously 
reported by our group. ${ }^{5}$ To this aim, derivatisation of the motor's structure through a functionalisation of the shorter $p$-methylphenylene arm with a long polyethylene glycol (PEG-24) chain was envisioned, using a propargylamide moiety as linker.

In this synthetic sequence, monofunctionalisation of key precursor $\mathbf{1}$ with tert-butyloxycarbonylprotected (BOC-protected) propargylamine was successfully achieved via a chemoselective Sonogashira cross-coupling under mild conditions. The resulting tetra( $p$-bromophenyl) cyclopentadienyl ruthenium complex $\mathbf{8}$, obtained in $75 \%$ yield, was further engaged in a four-fold Suzuki-Miyaura coupling with ferrocene boronic acid pinacol ester to give the corresponding tetraferrocenyl derivative 9 in a $16 \%$ yield. Deprotection of the propargylamine moiety was next conducted under mild conditions using trimethylsilyl triflate in the presence of lutidine. ${ }^{15}$ Indeed, standard BOC cleavage procedures involving trifluoroacetic acid led to decomposition of the Ru(II) complex, which appeared unstable under acidic conditions. Finally, the long PEG chain required for force spectroscopy experiments was covalently linked to the motor scaffold through a condensation between free propargylamine $\mathbf{1 0}$ and a monodisperse methoxy-PEG24-propionic acid partner, activated as an $\mathrm{N}$-hydroxysuccinimidyl ester. After $24 \mathrm{~h}$ at room temperature in the presence of triethylamine, the desired molecular winch prototype $\mathbf{1 1}$ was isolated in 69\% yield (from 9) and its structure was unambiguously confirmed by mass spectrometry and NMR spectroscopy.

In conclusion, the dissymmetric 1-(p-iodophenyl)-2,3,4,5-tetra( $p$-bromophenyl)cyclopentadienyl hydrotris(indazolyl)borate ruthenium(II) complex was efficiently prepared and subsequently used as a key building block in the modular synthesis of ruthenium-based molecular machines incorporating a dissymmetrised rotating platform. Indeed, selective functionalisation of the pre-activated precursor was achieved via palladium-catalysed "Sonogashira/Suzuki-Miyaura" cross-coupling sequences to afford new prototype of molecular winches and molecular gears. The mechanical studies on surface and at the single molecule scale are currently underway.

\section{Acknowledgements}

This work was supported by the University Paul Sabatier (Toulouse) and CNRS. It has received funding from the ANR (ACTION project ANR-15-CE29-0005), the European Union's Horizon 2020 research and innovation programme under the project MEMO, grant agreement No 766864, the JSPS KAKENHI grant in aid for Scientific Research on Innovative Areas "Molecular Engine (No.8006)" 18H05419. Y.G. thanks the MESR for a PhD Fellowship. Dr Colin Martin is warmly acknowledged for his careful reading and improving of our manuscript.

\section{References and Notes}

1. G. Rapenne, Org. Biomol. Chem., 2005, 3, 1165.

2. a) S. Kassem, T. van Leeuwen, A. S. Lubbe, M. R. Wilson, B. L. Feringa and D. A. Leigh, Chem. Soc. Rev., 2017, 46, 2592; b) Q. Li, G. Fuks, E. Moulin, M. Maaloum, M. Rawiso, I. Kulic, J. T. Foy and N. Giuseppone, Nat. Nanotechnol., 2015, 10, 161; c) Y. Zhang, J.P. Calupitan, T. Rojas, R. Tumbleson, G. Erbland, C. Kammerer, T.M. Ajayi, S. Wang, L.C. Curtiss, A.T. Ngo, S.E. Ulloa, G. Rapenne and S.W. Hla, Nature Commun., 2019, 10, 3742; d) G. Rapenne and C. Joachim, Nat. Rev. Mater., 2017, 2, 17040; e) A. Saywell, A. Bakker, J. Mielke, T. Kumagai, M. Wolf, V. Garcia-Lopez, P.-T. Chiang, J. M. Tour, L. Grill, ACS Nano 2016, 10, 10945-10952. 
3. a) J. Berna, D. A. Leigh, M. Lubomska, S. M. Mendoza, E. M. Perez, P. Rudolf, G. Teobaldi and F. Zerbetto, Nat. Mater., 2005, 4, 704; b) W. R. Browne and B. L. Feringa, Nat. Nanotechnol., 2006, 1, 25; c) R. Eelkema, M. M. Pollard, J. Vicario, N. Katsonis, B. S. Ramon, C. W. M. Bastiaansen, D. J. Broer and B. L. Feringa, Nature, 2006, 128, 14397.

4. a) H. L. Tierney, C. J. Murphy, A. D. Jewell, A. E. Baber, E. V. Iski, H. Y. Khodaverdian, A. F. McGuire, N. Klebanov and E. C. H. Sykes, Nat. Nanotechnol. 2011, 6, 625; b) R. Stefak, A. M. Sirven, S. Fukumoto, H. Nakagawa and G. Rapenne, Coord. Chem. Rev., 2015, 287, 79; c) J. Chen, J. Vachon and B. L. Feringa, J. Org. Chem. 2018 83, 6025.

5. G. Vives, H.-P. Jacquot de Rouville, A. Carella, J.-P. Launay and G. Rapenne, Chem. Soc. Rev., 2009, 38, 1551.

6. U. G. E. Perera, F. Ample, H. Kersell, Y. Zhang, G. Vives, J. Echeverria, M. Grisolia, G. Rapenne, C. Joachim and S.-W. Hla, Nat. Nanotechnol., 2013, 8, 46.

7. Y. Zhang, H. Kersell, R. Stefak, J. Echeverria, V. Iancu, U. G. E. Perera, Y. Li, A. Deshpande, K.-F. Braun, C. Joachim, G. Rapenne and S.-W. Hla, Nat. Nanotechnol., 2016, 11, 706.

8. P. Lussis, T. Svaldo-Lanero, A. Bertocco, C.-A. Fustin, D. A. Leigh and A.-S. Duwez, Nat. Nanotechnol., 2011, 6, 553; (b) A. Van Quaethem, P. Lussis, D. A. Leigh, A.-S. Duwez and C.-A. Fustin, Chem. Sci., 2014, 5, 1449; d) D. Sluysmans, S. Hubert, C. J. Bruns, Z. Zhu, J. F. Stoddart and A.-S. Duwez, Nat. Nanotechnol. 2018, 13, 209.

9. G. Erbland, S Abid, Y. Gisbert, N. Saffon-Merceron, Y. Hashimoto, L. Andreoni, T. Guérin, C. Kammerer and G. Rapenne, Chem. Eur. J., 2019, 25, in press.

10. C. Kammerer and G. Rapenne, Eur. J. Inorg. Chem., 2016, 2214.

11. Unpublished results.

12. R. Chinchilla and C. Najera, Chem. Rev., 2007, 107, 874.

13. G. Erbland, Y. Gisbert, G. Rapenne and C. Kammerer, Eur. J. Org. Chem., 2018, 4731.

14. Selected data for 1: $\mathrm{C}_{65} \mathrm{H}_{54} \mathrm{BBr}_{4} \mathrm{IN}_{6} \mathrm{RuS}_{3}, 3 / 2 \mathrm{CH}_{2} \mathrm{Cl}_{2} M=1701.13$, monoclinic, space group $P 2_{1} / c, a=$ $13.1648(6) \AA, b=24.9566(10) \AA, c=21.5935(9) \AA, \beta=107.569(2)^{\circ}, V=6763.6(5) \AA^{3}, Z=4$, crystal size $0.20 \times 0.12 \times 0.04 \mathrm{~mm}^{3}, 118682$ reflections collected (12080 independent, Rint $\left.=0.1196\right), 864$ parameters, 202 restraints, $R 1[\mathrm{I}>2 \sigma(\mathrm{I})]=0.0737, w R 2$ [all data] $=0.1953$, largest diff. peak and hole: 2.655 and $-2.104 \mathrm{e}^{-3}$. CCDC-1958243 contains the supplementary crystallographic data for this paper. These data can be obtained free of charge from The Cambridge Crystallographic Data Centre via www.ccdc.cam.a-c.uk/data request/cif.

15. A. J. Zhang, D. H. Russell, J. Zhu and K. Burgess, Tetrahedron Lett., 1998, 39, 7439. 